\title{
Colour influences sensory perception and liking of orange juice
}

\author{
Rocío Fernández-Vázquez ${ }^{1}$, Louise Hewson², lan Fisk², Dolores Hernanz Vila ${ }^{3}$, Francisco Jose Heredia Mira', \\ Isabel M Vicario ${ }^{1}$ and Joanne Hort ${ }^{2 *}$
}

\begin{abstract}
Background: This study assesses the effect of slight hue variations in orange juice (reddish to greenish) on perceived flavour intensity, sweetness, and sourness, and on expected and actual liking. A commercial orange juice (COJ) was selected as a control, and colour-modified orange juices were prepared by adding red or green food dyes (ROJ and GOJ) that did not alter the flavour of the juice. A series of paired comparison tests were performed by 30 naive panellists to determine the influence of orange juice colour on flavour intensity, sweetness, and sourness. Then, 100 orange juice consumers were asked to rate expected liking of orange juice samples initially by visual evaluation and subsequently for actual liking upon consumption, using a labelled affective magnitude scale.

Results: Results of pair comparison tests indicated that colour changes did not affect flavour intensity and sweetness, but the greenish hue (GOJ) significantly increased the perceived sourness. Results of the consumers' study indicated significant differences in expected liking between the orange juice samples, with ROJ having the highest expected liking. However, scores of actual liking after consumption were not significantly different. COJ and GOJ showed a significant increase in actual liking compared to expected liking.
\end{abstract}

Conclusions: This study shed light on how slight variations in orange juice hue (reddish to greenish hues) affect the perceived flavour intensity, sweetness, and sourness, and the expected and actual liking of orange juice.

Keywords: Colour, Consumer study, Orange juice, Pair comparison

\section{Background}

Orange juice $(\mathrm{OJ})$ is one of the most popular and more consumed juices in the world because of its sensory properties [1]. Among the quality attributes appreciated by consumers, colour has been highlighted as influencing consumer acceptance [2].

Flavour is defined as a "complex combination of the olfactory, gustatory, and trigeminal sensations perceived during tasting. The flavour may be influenced by tactile, thermal, painful, and/or kinaesthetic effects" [3]. Visual and auditory cues are not intrinsic to the flavour according to the ISO standard, although they may modify it [3]. Visual cues, such as a food's colour, may then modify the perception of a food's flavour by influencing the gustatory and olfactory attributes, and/or by influencing the overall multisensory flavour perception [4].

\footnotetext{
* Correspondence: joanne.hort@nottingham.ac.uk

${ }^{2}$ School of Biosciences, Division of Food Sciences, University of Nottingham, Sutton Bonington Campus, Loughborough, Leicestershire LE12 5RD, UK
} Full list of author information is available at the end of the article
Researchers have been investigating the influence of colour in taste, odour, and flavour (both on a theoretical and practical level) and also in acceptability of foods for decades; however, an unequivocal answer to how colour modifies taste, odour, and flavour has not, as yet, been reached. For example, studies by Maga [5], Clydesdale et al. [6], Huggart et al. [7], and Pangborn [8] found a correlation between colour and flavour perception. However, other studies have failed to demonstrate any such link between colour and sensory characteristics (e.g., Alley and Alley [9], Chan and Kane [10], Frank et al. [11], Gifford and Clydesdale [12], Gifford et al. [13], Zampini et al. [14,15]).

Recently, Wei et al. [16] quantified the relationships between OJ colour and observer response. They found that highly saturated OJ colours tended to be expected to have a stronger flavour; probably because it is the natural colour for OJ. However, this study examined only expected liking, as it was done on virtual OJ samples shown on computer screens. In a recent review, Zellner [17] discussed the literature on colour-odour correspondences including the effect 
on odour discrimination, odour intensity, and odour pleasantness, and concluded that the effects of colour on odour judgements are generally consistent. Studies by DuBose et al. [18], Christensen [19], Guinard and Souchard [20], and Zellner and Durlach [21], also claimed that appropriately coloured foods were perceived to have a stronger intensity of flavour and better quality than inappropriately coloured foods, but in these studies the panellists tasted the samples, not only observed them.

It is a widely accepted fact that food can be more or less appealing because of its appearance, before testing it $[4,22]$. Hedonic quality was also found to be influenced by colour. Influence of $\mathrm{OJ}$ colour on appearance and flavour was studied by Schutz [23] and the results showed that observers preferred the appearance of an orange coloured juice over a yellow coloured juice. Furthermore, Clydesdale et al. [24] suggested that colour influence could be a result from learned association rather than from inherent psychological characteristics.

Thus far, few studies have investigated modest colour changes in OJs without modifying other characteristics such as flavour and sweetness. Tepper [25] was the first to explore how a small amount of green food colouring added to OJ influenced flavour, sweetness, and overall liking. The study suggested that acceptance of consumers was reduced by the green colour but had little influence on flavour, sweetness, and overall liking. Here, we have widened the objectives of the investigation to include a wider range of hues (using green and red food colouring) and attributes evaluated (flavour, sweetness, and sourness). We have evaluated expected liking and actual liking, which is a relevant aspect since colour is the first attribute evaluated by consumers prior to consumption, and, finally, differences among groups of consumers were also explored.

\section{Results and discussion}

Instrumental colour characterization

In Figure 1, the CIELAB colour space [26] ( $a * b *$ plane) illustrates the colour of the samples included in this study as measured by colorimetry. It can be observed that the greenish coloured OJ (GOJ) showed lower values of $a$;, while the reddish coloured OJ (ROJ) showed the highest value. The control OJ (COJ) was placed between the other two groups. The averages of the coordinate $L^{*}$ were 47.94, 46.84, and 46.08 for GOJ, ROJ, and COJ, respectively. Accordingly, the hue angle was lower for the ROJ $\left(84.70^{\circ}\right)$ and higher for the GOJ $\left(97.28^{\circ}\right)$, while the COJ value $\left(94.25^{\circ}\right)$ was nearer to the GOJ.

$\Delta \mathrm{E}^{*}$ ab for the samples was calculated with mean values for $L^{*}, a^{*}$, and $b^{*}$ corresponding to each OJ, to ensure that the differences between samples could be noticed by the panellists. Results were 5.97, 2.84, and 3.49, between samples GOJ-ROJ, GOJ-COJ, and ROJ-COJ, respectively.
These values are over the range 0.38-0.73 CIELAB units and over 1.75 CIELAB units, which are considered as the threshold and suprathreshold colour differences, respectively [27]. This means that samples were slightly different and that these differences should be perceived by a normalvision human eye.

\section{Sensory evaluation \\ Influence of colour on perceived sweetness, sourness, and orange juice flavour}

Results from triangle tests comparing the $\mathrm{COJ}$ and the colour-modified samples, ROJ or GOJ, provided insufficient evidence to conclude that either of the two colour-modified samples were perceptibly different to the COJ $(\alpha=0.05)$ confirming that the dye had no influence on taste, flavour, or texture.

\section{Influence of colour on sweetness perception}

Comparisons for sweetness did not show significant differences in COJ-ROJ, COJ-GOJ or GOJ-ROJ $(P>0.05$ in all of the cases), so across the range of colour differences in this study, sweetness did not appear to be influenced by colour. Results in this study are in agreement with those reported by Tepper [25] related to slight green colour variation in $\mathrm{OJ}$ (no effect on sweetness perception was found). Moreover, studies in other beverages and solutions also have reported similar findings. Frank et al. [11] reported that adding red food colouring to either an odourless or strawberry odour-sweetened aqueous samples failed to increase perceived sweetness ratings of the orange redlooking drinks relative to participants' assessment of the clear drinks; Alley and Alley [9] reported no effect by the addition of colour (red, blue, yellow, and green) when compared to a clear, no-colour-added baseline, on participants' ratings of the sweetness of either sweetened water or gelatine samples; Zampini et al. [14] also failed to demonstrate an easily interpretable effect of variations in colour intensity on perceived sweetness intensity. On the other hand, Johnson and Clydesdale [28] found that, on average, when odourless solutions were red coloured (with different intensities), participants could more easily detect the presence of sucrose than when they were uncoloured, though the intensity of the colour did not have a significant effect on their performance.

\section{Influence of colour on sourness perception}

Sourness perception was significantly affected in the pair COJ-GOJ $(P<0.05)$ with the GOJ detected as the sourest sample. Hence the panellists were influenced by green colour when they evaluated the sourness. Surprisingly, in the ROJ-GOJ pair, no significant difference was found, although these lack of detected difference could be due to the larger differences in colour between both OJs $\left(\Delta \mathrm{E}_{\mathrm{ab}}^{*}=5.97\right)$, which would confuse the panellists 


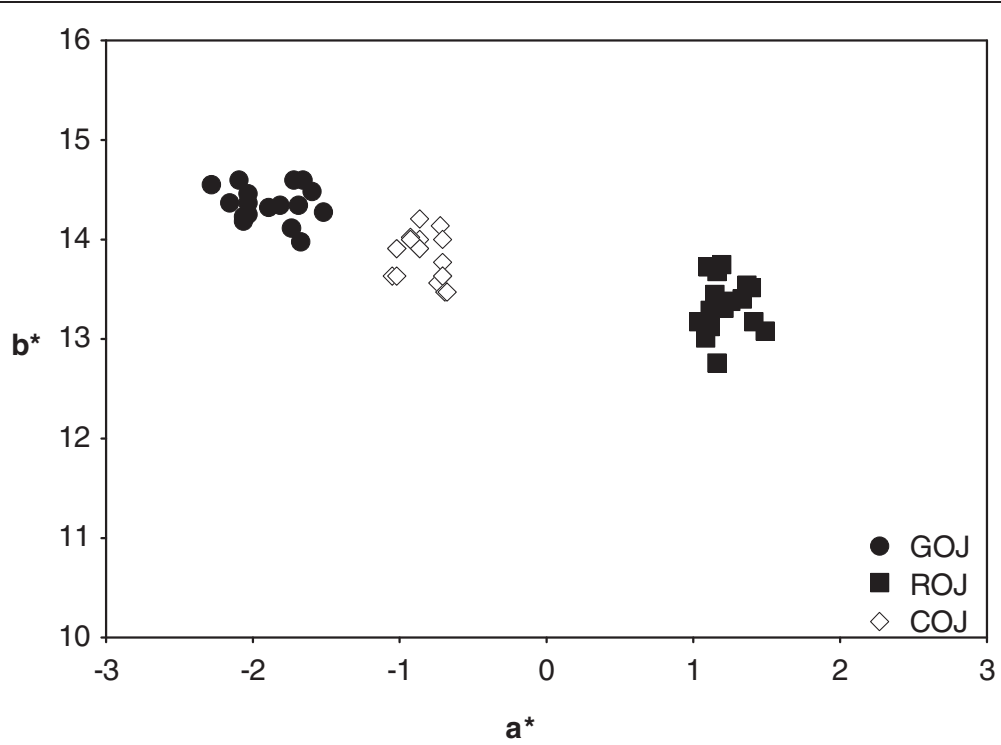

Figure 1 Colour coordinates of samples in the $\boldsymbol{a}^{*} \boldsymbol{b}^{*}$ plane. (COJ: Control orange juice; GOJ: Greenish orange juice; ROJ: Reddish orange juice).

in their evaluations. Other studies obtained similar results, for example Pangborn [8] demonstrated that green food colouring enhanced sourness ratings in pear nectar, though it should be noted that Pangborn [29] subsequently failed to replicate this finding. Furthermore, contrary to these results, Maga [5] reported that green and yellow colorants in water solutions decreased sour taste sensitivity and red colouring had no effect.

\section{Influence of colour on flavour perception}

When flavour perception was explored, again, no statistically significant differences were found in any of the comparisons (GOJ-COJ, ROJ-COJ, and GOJ-ROJ), in accordance with findings reported by Tepper [25], who concluded that slight colour variation in $\mathrm{OJ}$ had little influence in flavour. On the other hand, DuBose et al. [17] reported that overall flavour intensity was affected by colour intensity, with higher colour intensity solutions giving rise to stronger flavour evaluation responses by participants for orange-flavoured beverages. Zellner's review [17] has indicated that many studies see a reduction in flavour intensity with increased colour but this was not the case in this study. Meanwhile, Kostyla [30] reported that the addition of yellow and blue colour to sweetened cherryflavoured beverages decreased flavour ratings while the addition of red colouring increased sweetness.

\section{Influence of colour on expected and actual liking}

Demographic and OJ consumption habits of the 100 consumers were recorded. Among the 100 consumers, the majority were females (66\%), between 18 and 25 years of age (57\%). In terms of consumption habits, $38 \%$ of the consumers consumed OJ less than once a week, $18 \%$ once a week, $12 \%$ twice a week, and finally, $32 \%$ of consumers consumed OJ more than twice a week. The most frequently consumed OJ was from concentrate (51\%), followed by freshly squeezed (44\%), and only $5 \%$ of consumers reported to consume homemade OJ. Finally, the most frequently consumed brand was Tropicana (33\%) which was the one chosen for this study, followed by other retailed brands as Tesco and Sainsbury's (19\% and 13\%, respectively).

Results showed significant differences in expected liking, with the ROJ scoring highest (mean 69.03) (Table 1). This is likely to relate to the association of more reddish hues in a freshly squeezed OJ indicating superior quality [31-33]. However, there were no significant differences in actual liking between any of the samples, which is in accordance with Tepper [25], who concluded that slight green colour variation reduced consumer acceptance regarding colour, but had little influence on overall liking. Moreover, it can be observed that when comparing expected liking with actual liking, there was a significant increase in actual liking of COJ and GOJ, suggesting that the real colour of the control sample (COJ) and the modification of the OJ colour towards greenish hues caused a negative impact on consumers expected liking.

Table 1 Mean and standard deviation scores for the samples

\begin{tabular}{ccc}
\hline & Expected liking & Actual liking \\
\hline Control OJ & $62.59 \pm 17.73^{\mathrm{a}, 1}$ & $66.40 \pm 18.06^{\mathrm{b}, 1}$ \\
Red OJ & $69.03 \pm 12.81^{\mathrm{a}, 2}$ & $68.48 \pm 15.89^{\mathrm{a}, 1}$ \\
Green OJ & $64.18 \pm 15.21^{\mathrm{a}, 1}$ & $69.34 \pm 14.13^{\mathrm{b}, 1}$ \\
\hline
\end{tabular}

Different letters superscripts within rows and different numbers within columns indicate statistically significant differences $(P<0.05)$. 


\section{Cluster analysis}

In order to find out if there were groups of consumers differing in expected and actual liking, a segmentation of the panel group was done by Cluster analysis [34] and three groups of consumers were clearly identified (Figure 2).

Characteristics of each cluster in terms of demography and OJ consumption are shown in Table 2. No marked differences in demographic characteristics were found. However, differences in OJ consumption frequency was observed; cluster 1 consumed OJ more frequently than the other clusters, with $44.2 \%$ consuming OJ more than twice a week in comparison to $15 \%$ and $21.4 \%$ of consumers in clusters 2 and 3, respectively. In terms of the kind and brands of the OJ most commonly consumed, clear differences were also found. Cluster 2 have a higher consumption of Morrisons (19\%) compared to other clusters but not compared to their consumption of other brands, moreover they reported a higher consumption of homemade OJ (10\%). While in cluster 3, concentrate OJ (57.1\%) was primarily consumed followed by freshly squeezed (39.3\%), and in cluster 1 more people reported to consume freshly squeezed OJ followed by concentrate OJ (51.9\% and $44.2 \%$, respectively). Different kinds and brands of OJ have different colours [35], and this may have influenced the consumer scores, as they would be familiar with a certain colour in OJ. These findings agree with Clydesdale et al. [24], confirming the possible influence of a learned association in the role of colour in consumer acceptance. Scores for the samples given by each cluster are reflected in Table 3 .

\section{Differences among samples in expected and actual liking}

Cluster 1 (52\%), the group with the most frequent OJ consumers, scored all samples higher for expected and actual liking than the other clusters and showed no significant differences in either expected or actual liking between the samples (Table 3). However, Cluster 2 (20\%) scored the control sample significantly lower in expected and actual liking compared to the colour-modified samples (average 38.80 and 46.90, respectively). Interestingly, this cluster consumed the Tropicana brand (the control sample in this study) less than the other clusters and this may account for the observed lower scores. In Cluster 3 (28.28\%), GOJ was scored significantly lower than the other samples for expected liking (47.71 as opposed to 61.96 and 63.14 for $\mathrm{COJ}$ and ROJ, respectively) whilst COJ was scored significant higher than the other samples for actual liking (68.43 in front of 56.89 and 56.50 for ROJ and GOJ, respectively).

\section{Expected liking vs. actual liking}

Consumers in cluster 1 showed significant differences between expected and actual liking for ROJ and GOJ.

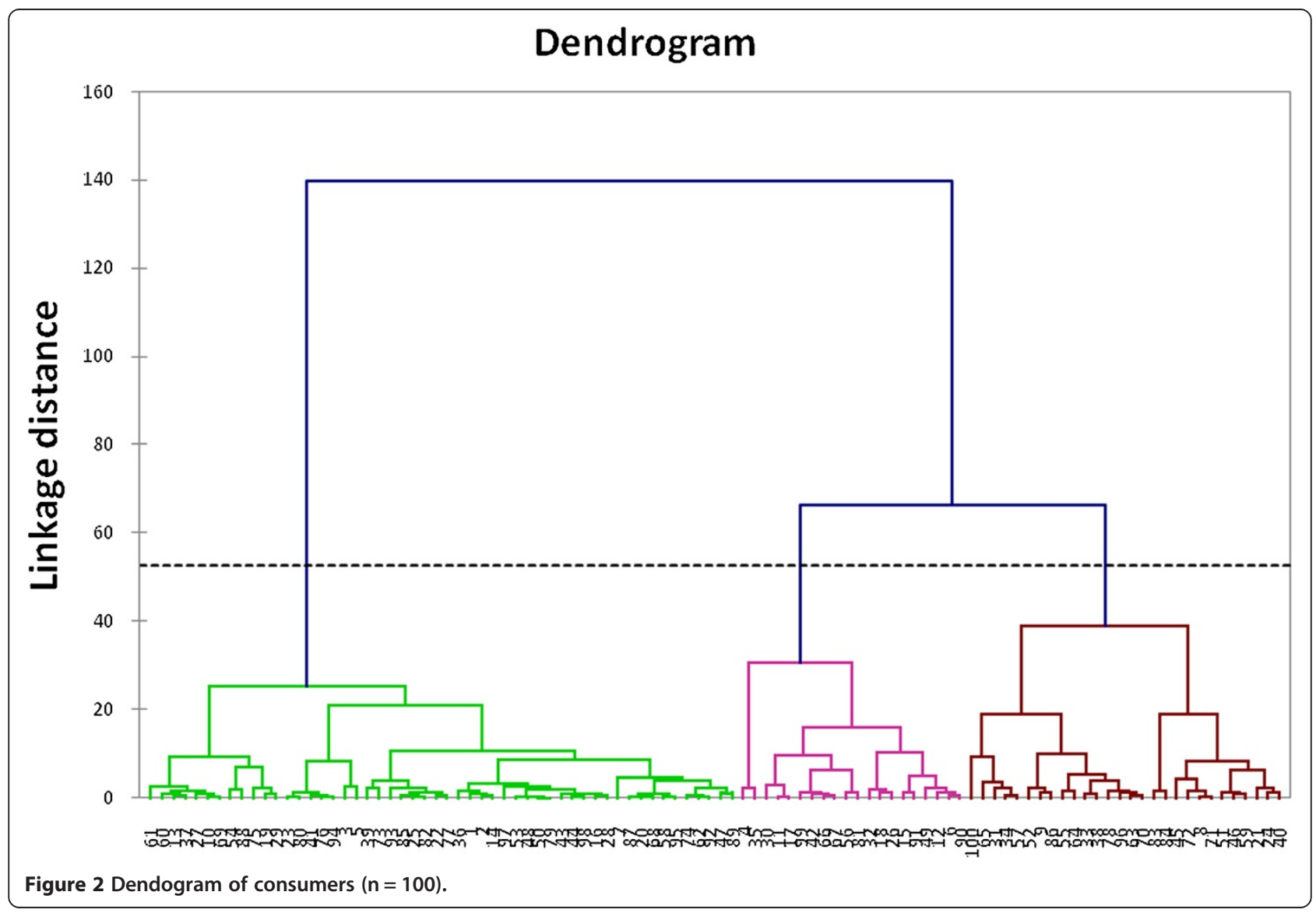


Table 2 Demographic characteristics and OJ consumption habits for each cluster

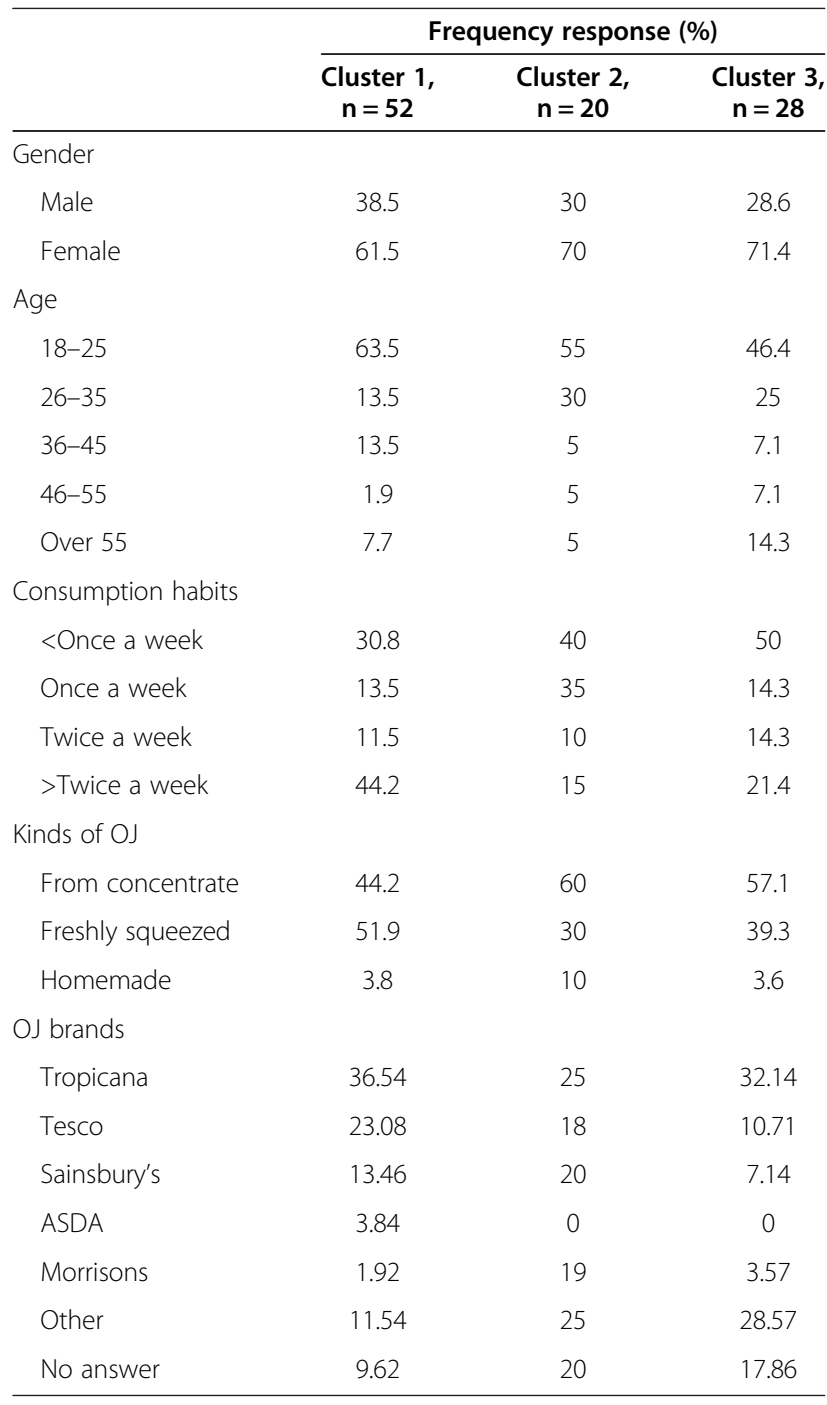

For these consumers, colour hue variation in relation to $\mathrm{COJ}$ had a negative influence on expected liking as scores were lower than for actually liking. In cluster 2 , significant differences between expected and overall liking were not found for any of the samples. Finally, Cluster 3 was clearly influenced in a negative way by the green appearance of GOJ scoring it the lowest in expected liking (mean 47.71). However, upon consumption of the sample, liking increased (actual liking score mean 56.50). There were no significant differences in this cluster between expected and actual liking for $\mathrm{COJ}$ and $\mathrm{ROJ}$ samples.

In general, these results, agree with results published previously by Fernández-Vázquez et al. [32], suggesting that no clear preferences for any colour was observed but that there are subsections of the population that show different preferences for OJ colour. They found that consumer clusters did not differ in terms of gender, age, or consumption habits indicating that these variables did not influence colour preference patterns. Other previous studies on consumer's colour acceptance of a different product (strawberry nectar from puree) have shown similar results, indicating that neither gender nor age or consumption habits had a significant impact on colour acceptance [36].

\section{Internal preference mapping}

Internal preference mapping refers to the analysis of preference data only and it was conducted to visualize the behaviour of the clusters of consumers. Two preference dimensions accounted for $86.18 \%$ of the total variance, so the third preference dimension was not considered. In Figure 3, it can be observed that the second dimension clearly separated the actual liking for the three OJs (positive values) from the expected liking (negative values). In COJ and ROJ, actual liking and expected liking were not significantly separated; this was not the case for GOJ for which expected and actual liking were clearly separated.

Considering actual liking, cluster 1 showed preferences for ROJ and GOJ, while cluster 3 was clearly closer to $\mathrm{COJ}$, indicating an increase in the scores after tasting the OJs. However, cluster 2, which was situated in the lower half of the second dimension, did not show any preference for any of the OJs after tasting them. On the other hand, this cluster (2) showed a clear preference for ROJ but only before tasting it.

\section{Conclusions and implications}

In this research, adjusting $\mathrm{OJ}$ colour towards more greenish hues was found to increase sourness perception, while variations to more reddish hues did not have any effect. Sweetness and flavour perception were not affected by colour variation. When expected and actual liking scores of colour-modified OJs were evaluated using a consumer panel, some interesting results were observed. While ROJ scores were similar for both expected and actual liking,

Table 3 Mean and standard deviation scores for the samples in each cluster

\begin{tabular}{clcc}
\hline \multicolumn{1}{c}{ Cluster } & Samples & Expected liking & Actual liking \\
\hline $1(\mathrm{n}=52,52 \%)$ & Control OJ & $72.08 \pm 9.78^{\mathrm{a}, 1}$ & $72.81 \pm 13.20^{\mathrm{a}, 1}$ \\
& Red OJ & $72.06 \pm 11.20^{\mathrm{a}, 1}$ & $76.35 \pm 8.71^{\mathrm{b}, 1}$ \\
& Green OJ & $72.06 \pm 9.92^{\mathrm{a}, 1}$ & $77.17 \pm 10.15^{\mathrm{b}, 1}$ \\
$2(\mathrm{n}=20,20 \%)$ & Control OJ & $38.80 \pm 11.69^{\mathrm{a}, 1}$ & $46.90 \pm 18.58^{\mathrm{a}, 1}$ \\
& Red OJ & $69.40 \pm 15.44^{\mathrm{a}, 2}$ & $64.25 \pm 17.01^{\mathrm{a}, 2}$ \\
& Green OJ & $66.75 \pm 8.56^{\mathrm{a}, 2}$ & $66.95 \pm 11.09^{\mathrm{a}, 2}$ \\
$3(\mathrm{n}=28,28 \%)$ & Control OJ & $61.96 \pm 16.82^{\mathrm{a}, 1}$ & $68.43 \pm 16.09^{\mathrm{a}, 1}$ \\
& Red OJ & $63.14 \pm 11.97^{\mathrm{a}, 1}$ & $56.89 \pm 17.53^{\mathrm{a}, 2}$ \\
& Green OJ & $47.71 \pm 14.32^{\mathrm{a}, 2}$ & $56.50 \pm 12.57^{\mathrm{b}, 2}$ \\
\hline
\end{tabular}

Different superscripts letters within rows and different numbers within columns for each cluster indicate statistically significant differences $(P<0.05)$. 


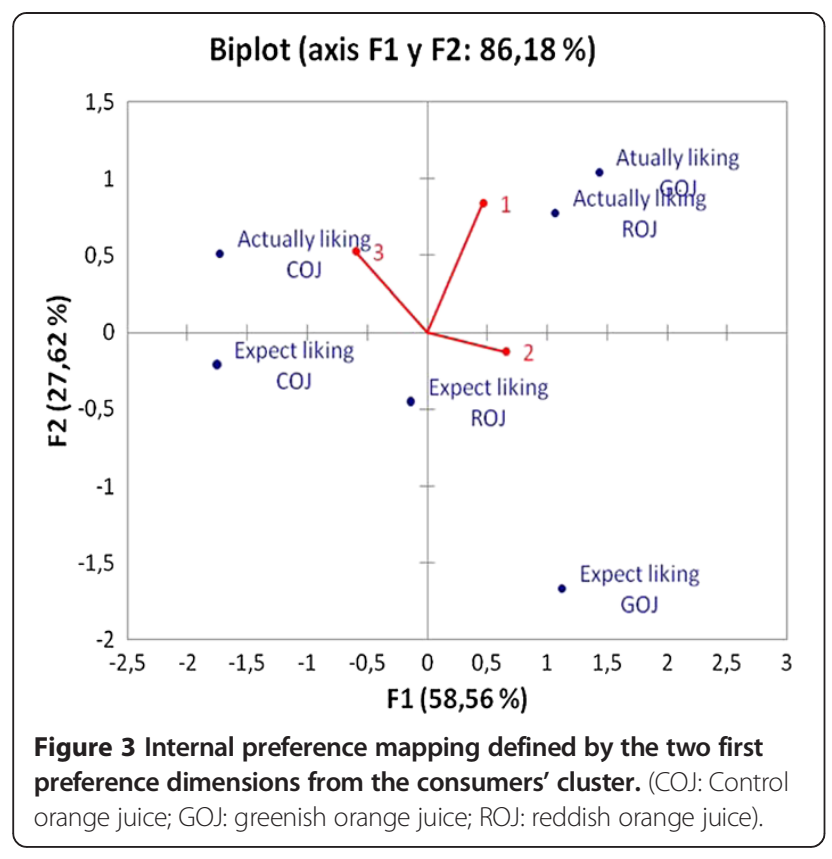

$\mathrm{COJ}$ and GOJ were evaluated significantly different after tasting. Greenish OJs were scored low before tasting which could be explained by the fact that fruits are usually greener in their first ripening stages, and therefore less sweet. Cluster analysis showed different OJ preferences for different groups of the population. No relationship with demographic characteristics were found in the clusters, although consumption habits (brands, type of OJ, and frequency of consumption) were more related to expected and actual liking of OJ, confirming the possible effect of learned association in colour influence. Some groups of the population were more affected than others by colour. In cluster 1 , colour hue variation in relation to COJ had a negative influence on the expected liking and cluster 3 was clearly negatively influenced by green colour. However, significant differences between expected and overall liking were not found in cluster 2. The impact of colour on sensory perception remains inconclusive and more research is needed to understand its influence on perception and liking in different products, since it seems to be product-specific. Nevertheless, it is clear that the food industry needs to continue to take into account the importance of measuring colour as part of quality control due to its possible influences on consumer flavour perception.

\section{Methods}

\section{Samples}

A commercial fresh OJ (Tropicana, United Kingdom) was selected to be the control OJ (COJ). Two colour modified samples were prepared by addition of food colourings (Supercook, United Kingdom); 50 mg/L red food colouring $(\mathrm{ROJ})$ or $250 \mathrm{mg} / \mathrm{L}$ green food colouring (GOJ). The amount of food colouring added was selected in order to get a modification in colour enough to be perceived by panellists but not too much in order to obtain samples with a realistic OJ colour. With this aim, the samples' colour was then measured, and colour differences between samples were also calculated. All samples presented to subjects were commercially available products. Participants were notified of the nature of the products and all signed to indicate they had given informed consent to participate.

\section{Instrumental colour characterisation}

A Hunterlab Colour Quest XE colorimeter (Universal Software V. 4.1) was used for colour measurements. Samples were measured in triplicate in a $10 \mathrm{~mm}$ glass cuvette (original Minolta). CIELAB [26] coordinates $\left(L^{*}, a^{*}, b^{*}\right)$ were obtained directly from the instrument. The colour value " $L$ ", measuring lightness, is quantified on a scale from 0 to 100 . The colour value " $a$ " quantifies red (positive values) to green (negative values), and the colour value " $b$ "* quantifies yellow (positive values) to blue (negative values). From the uniform colour space, the psychological parameters chroma $\left(\mathrm{C}^{*}{ }_{\mathrm{ab}}\right)$ and hue $\left(\mathrm{h}_{\mathrm{ab}}\right)$ are defined:

$$
\begin{aligned}
& C_{a b}^{*}=\left[\left(a^{*}\right)^{2}+\left(b^{*}\right)^{2}\right]^{1 / 2} \\
& h_{a b}=\arctan \left(b^{*} / a^{*}\right)
\end{aligned}
$$

$\mathrm{C}_{\mathrm{ab}}^{*}$ represents the quantitative attribute of colourfulness and is used to determine the degree of difference of a hue in comparison to a grey colour with the same lightness. $h_{a b}$ represents the qualitative attribute according to which colours have been traditionally defined as reddish, greenish, etc., and is used to define the difference of a colour with reference to a grey colour with the same lightness [37].

Colour differences $\left(\Delta \mathrm{E}_{\mathrm{ab}}^{*}\right)$, which are very important to evaluate the relationships between visual and numerical analyses [38], were calculated as the Euclidean distance between two points in the 3-D space defined by $L^{*}, a^{*}$, and $b^{*}$.

\section{Sensory evaluation \\ Influence of colour on perceived sweetness, sourness, and orange juice flavour}

Firstly, to identify if the addition of the food colouring had any physicochemical effect that may impact flavour perception, an overall difference test (triangle test, [39]) was performed comparing both colour modified OJ's with the control OJ. Twelve naive assessors were recruited from staff and students at the University of Nottingham to take part in the study. Two triangle tests were performed (COJ vs. $\mathrm{ROJ}$ and $\mathrm{COJ}$ vs. GOJ). For each test, assessors were presented with three samples, told two were identical and asked to determine the odd sample. Samples $(15 \mathrm{~mL})$ were presented in dark amber glass bottles, labelled with random 
3-digit codes, in a randomized order across the panel and under red light conditions to ensure no visual cues were available to panellists.

To examine the influence of colour modification on perception, a series of attribute-specific difference tests were performed (Paired comparison, [40]). Thirty untrained assessors were recruited from staff and students of the University of Nottingham. Multiple pairwise comparison tests compared all combinations of COJ, ROJ, and GOJ for each attribute of interest - sweetness, sourness, and OJ flavour. For each paired comparison, assessors were presented with two samples and asked to determine which was the most intense for the attribute in question. Samples $(15 \mathrm{~mL})$ were presented in clear glass vials, labelled with random 3-digit codes and the order randomised across the panel.

\section{Influence of colour on expected and actual liking of orange juice}

One hundred European OJ consumers were recruited from staff and students of the University of Nottingham to take part in the study. Information regarding demographics and consumption and purchase habits were collected via a questionnaire prior to the sensory assessment of the samples. A labelled affective magnitude scale (LAM) was presented for consumers to rate expected liking of each of the three OJs (COJ, ROJ, and GOJ) based on visual assessment only. A second LAM scale was used for consumers to rate actual liking of the products following consumption. Samples $(15 \mathrm{~mL})$ were presented monadically in clear glass vials, labelled with random 3-digit codes, in a randomised order across the panel.

All sensory testing was carried out in purpose designed individual sensory booths, under Northern Hemisphere lighting conditions. Unsalted cracker (Rakusen's, UK) and mineral water (Evian, France) were available for assessors to palate cleanse before and between tasting samples. Data was captured using Fizz Network sensory software (Biosystemes, France).

\section{Data analysis}

Discrimination tests (triangle and paired comparisons) were analysed using Fizz Calculations software (Biosystemes, France). Consumer data first underwent normality testing (Shapiro-Wilk test) and was subsequently analysed using non-parametric tests to identify differences between samples (Wilcoxon test) with Statistica 8 for Windows (StatSoft, 2007), and XLStat (Version 2009.6.03, Addinsoft, USA). Consumer data were further examined using hierarchal cluster analysis, using Squared Euclidean Distances and Wards criterion, and internal preference mapping (XLStat).

\section{Abbreviations}

COJ: Control orange juice; GOJ: Greenish orange juice; LAM: Labelled affective magnitude scale; OJ: Orange juice; ROJ: Reddish orange juice.

\section{Competing interests}

The authors declare that they have no competing interests.

\section{Authors' contributions}

IMV, FJH, and DH conceived the idea of the study. JH and $\mathrm{LH}$ designed the details. RFV conducted the study, analysed the data, and wrote the manuscript. JH, LH, and IF read and approved the final manuscript. All authors read and approved the final manuscript.

\section{Acknowledgements}

This work was supported by funding from the Consejería de Innovación Ciencia y Empresa, Junta de Andalucía by the project P08-AGR-03784. RFV holds a grant from the Conserjería de Innovación Ciencia y Empresa, Junta de Andalucía.

\section{Author details}

${ }^{1}$ Food Colour \& Quality Laboratory, Department of Nutrition \& Food Science, Universidad de Sevilla Facultad de Farmacia, 41012 Sevilla, Spain. ${ }^{2}$ School of Biosciences, Division of Food Sciences, University of Nottingham, Sutton Bonington Campus, Loughborough, Leicestershire LE12 5RD, UK.

${ }^{3}$ Department of Analytical Chemistry, Universidad de Sevilla, Facultad de Farmacia, 41012 Sevilla, Spain.

Received: 1 October 2013 Accepted: 17 December 2013

Published: 17 January 2014

\section{References}

1. Rouseff RL, Ruiz Perez-Cacho P, Jabalpurwala F: Historical review of citrus flavor research during the past 100 years. J Agr Food Chem 2009, 57:8115-8124.

2. Melendez-Martinez AJ, Vicario IM, Heredia FJ: El color del zumo de naranja (II): aspectos físicos: "Orange juice colour (II): physical aspects". Alimentación, Equipos y Tecnología 2004, 186:103-106.

3. ISO: Standard 5492: terms relating to sensory analysis. Geneva: International Organization for Standardization; 1992.

4. Spence C, Levitan CA, Shankar MU, Zampini M: Does food color influence taste and flavor perception in humans? Chemosensory Percep 2010, 3:68-84.

5. Maga JA: Influence of color on taste thresholds. Chem Sens Flav 1974, 1:115-119.

6. Clydesdale FM, Gover R, Fugardi C: The effect of color on thirst quenching, sweetness, acceptability and flavour intensity in fruit punch flavored beverages. J Food Quality 1992, 15:19-38.

7. Huggart RL, Petrus DR, Buzz Lig BS: Color aspects of Florida commercial grapefruit juices. Proc Fla State Horticultural Soc 1977, 90:173-175.

8. Pangborn RM: Influence of color on the discrimination of sweetness. Am J Psychol 1960, 73:229-238.

9. Alley RL, Alley TR: The influence of physical state and color on perceived sweetness. J Psychol: Interdiscip Appl 1998, 132:561-568.

10. Chan MM, Kane-Martinelly C: The effect of color on perceived flavor intensity and acceptance of foods by young adults and elderly adults. J Ame Diet Assoc 1997, 132:561-568.

11. Frank RA, Ducheny K, Mize SJ: Strawberry odor, but not red color, enhances the sweetness of sucrose solutions. Chem Sens 1989, 14:371-377.

12. Gifford SR, Clydesdale FM: The psychophysical relationship between color and sodium chloride concentrations in model systems. J Food Prot 1986, 49:977-982

13. Gifford SR, Clydesdale FM, Damon RA: The psychophysical relationship between color and salt concentrations in chicken flavored broths. J Sens Stud 1987, 2:137-147.

14. Zampini M, Sanabria D, Phillips N, Spence C: The multisensory perception of flavor: assessing the influence of color cues on flavor discrimination responses. Food Qual Prefer 2007, 18:975-984.

15. Zampini M, Wantling E, Phillips N, Spence C: Multisensory flavor perception: assessing the influence of fruit acids and color cues on the perception of fruit-flavored beverages. Food Qual Prefer 2008, 19:335-343.

16. Wei S-T, Ou L-C, Luo MR, Hutchings JB: Optimisation of food expectations using product colour and appearance. Food Qual Prefer 2012, 23:49-62. 
17. Zellner DA: Color-odor interactions: a review and model. Chemosens Percep 2013, 6:155-169.

18. DuBose CN, Cardello AV, Maller O: Effects of colorants and flavorants on identification, perceived flavor intensity, and hedonic intensity, and hedonic quality of fruit-flavored beverages and cake. J Food Sci 1980, 45:1393-1399.

19. Christensen CM: Effects of color on aroma, flavor and texture judgments of foods. J Food Sci 1983, 48:787-790.

20. Guinard J, Souchrd A, Picot M, Rogeaux MSJM: Determinants of the thirst-quenching character of beer. Appetite 1998, 31:101-115.

21. Zellner DA, Durlach P: Effect on color on expected and experienced refreshment, intensity, and liking of beverages. Am J Psychol 2003, 116:633-647.

22. Piqueras-Fiszman B, Giboreau A, Spence C: Assessing the influence of the color of the plate on the perception of a complex food in a restaurant setting. Flavour 2013, 2:24.

23. Schutz HG: Colour in relation to food preference. In Colour in Foods, A Symposium. Edited by Farrell KT, Wagner JR, Peterson MS, Mackinney G. Washington, DC: Natl Acad Sci, Natl Research Council; 1954:16-21.

24. Clydesdale FM: Colour as a factor in food choice. Crit Rev Food Sci Nutr 1993, 33:83-101.

25. Tepper BJ: Effects of a slight color variation on consumer acceptance of orange juice. J Sens Stud 1993, 8:145-154.

26. CIE: Recommendations on Uniform Color Spaces, Color-Difference Equations, Psychometric Color Terms, CIE Publication No. 15 (E-1.3.1) 1971, Supplement 2. Vienna: Bureau Central de la CIE; 1978.

27. Martínez JA, Melgosa M, Pérez MM, Hita E, Negueruela Al: Note: visual and instrumental color evaluation in red wines. Food Sci Technol Int 2001, 7:439-444.

28. Johnson J, Clydesdale FM: Perceived sweetness and redness in colored sucrose solutions. J Food Sci 1982, 47:747-752.

29. Pangborn RMHB: The influence of color on discrimination of sweetness and sourness in pear-nectar. Am J Psychol 1963, 76:315-317.

30. Kostyla AS: The Psychophysical Relationships Between Color and Flavor of Some Fruit Flavored Beverages. PhD Thesis. Amherst: University of Massachusetts; 1978.

31. Meléndez-Martínez AJ, Gómez-Robledo L, Melgosa M, Vicario IM, Heredia FJ: Color of orange juices in relation to their carotenoid contents as assessed from different spectroscopic data. J Food Compos Anal 2011, 24:837-844.

32. Stinco C, Fernández-Vázquez R, Escudero-Gilete ML, Heredia FJ, MelendezMartinez AJ, Vicario IM: Effect of orange juice's processing on the color, particle size, and bioaccessibility of carotenoids. J Agric Food Chem 2012, 60:1447-1455.

33. Fernández-Vázquez R, Stinco C, Melendez-Martinez AJ, Heredia FJ, Vicario IM: Visual and instrumental evaluation of orange juice color: a consumers' preference study. J Sens Stud 2011, 26:436-444.

34. Vigneau E, Qannari EM, Punter PH, Knoops S: Segmentation of a panel of consumers using clustering of variables around latent directions of preference. Food Qual Prefer 2007, 12:359-363.

35. Fernández-Vázquez R, Stinco C, Escudero-Gilete ML, Melendez-Martinez AJ, Heredia FJ, Vicario IM: Estudio preliminar sobre la utilidad del color para clasificar los zumos de naranja según su elaboración: "Preliminary study on the utility of colour to classify orange juices attending to their processing". Optica Pura y Aplicada 2010, 43:245-249.

36. Gossinger M, Mayer F, Radochan N, Höfler M, Boner A, Grolle E, Nosko E, Bauer R, Berchofer E: Consumer's color acceptance of strawberry nectars from puree. J Sens Stud 2009, 24:78-92.

37. Meléndez-Martínez AJ, Vicario IM, Heredia FJ: Correlation between visual and instrumental colour measurements of orange juice dilutions: effect of the background. Food Qual Prefer 2005, 16:471-478.

38. Melgosa M, Hita E, Poza AJ, Alman DH, Berns RS: Suprathreshold color-difference ellipsoids for surface colors. Color Res App/ 1997, 22:148-155.

39. ISO 4120:2005: Sensory analysis: methodology: triangle test. Geneva: International Organization for Standardization; 2005.

40. ISO 5495:2005: Sensory analysis: methodology: paired comparison test. Geneva: International Organization for Standardization; 2005.

\section{Submit your next manuscript to BioMed Central and take full advantage of:}

- Convenient online submission

- Thorough peer review

- No space constraints or color figure charges

- Immediate publication on acceptance

- Inclusion in PubMed, CAS, Scopus and Google Scholar

- Research which is freely available for redistribution 